\title{
Latina/o Adolescents in an Emerging Immigrant Community: A Qualitative Exploration of their Future Goals
}

\author{
Laura M. Gonzalez, Gabriela L. Stein, and Laura R. Shannonhouse \\ The University of North Carolina at Greensboro
}

Mitchell J. Prinstein

The University of North Carolina at Chapel Hill

\begin{abstract}
Although immigrant adolescents typically have high hopes for their futures, educational and career outcomes often do not match aspirations. The future aspirations of 17 Latina/o adolescents in an emerging immigrant community were explored. Qualitative interviews were conducted and analyzed using consensual qualitative research methodology (CQR). Interviews focused on goals for education/career and supports and barriers to reaching those goals. Overall, students expressed high aspirations but were unclear on how to achieve them. Family members and school personnel were seen as supportive, but with limitations. Barriers mentioned by most participants included early pregnancy, finances, and circumstances beyond their control; they declined to endorse other barriers when prompted. Students also held less optimistic views of the educational and career possibilities of an "average" Latina/o/a as compared to their own goals, which is framed in terms of stereotypes. A clear theme emerged where students placed the primary responsibility for their success or failure on themselves without acknowledging many barriers in the environment. Findings are discussed from a social justice point of view with implications that pertain to provision of college planning information, context for applying it, affective support, and systemic advocacy.
\end{abstract}

Keywords. Latina/o or Hispanic, emerging immigrant community, educational goals, educational barriers, qualitative research

\section{Introduction}

Immigrant families often make the difficult choice to leave their home countries because they are seeking better opportunities in the host country - economic opportunities for the adult generation and educational opportunities for the children (Hill \& Torres, 2010). Unfortunately, national reports document that the educational aspirations of recent Latina/o immigrant families 
do not always translate into positive outcomes. Data presented by the Pew Hispanic Center (2009) indicate that $89 \%$ of Latina/o adolescents identify a college education as valuable for success in life, but far fewer (60\% of native born Latinas/os and $29 \%$ of foreign born Latinas/os) plan to obtain a bachelor's degree themselves. Although college participation rates have increased, only $12 \%$ of Mexican-born or Central American-born adolescents age 18-24 were enrolled in US colleges in 2010. Caribbean-born (37\%) and South American-born (44\%) adolescents were participating at higher rates (Patten, 2012). This is important because education remains one of the primary ways to improve one's economic or occupational circumstances, and many Mexican and Central American immigrant families have labor intensive jobs with relatively little pay (Patten). Counselors or other advocates in leadership positions could play a pivotal role in fostering social justice by helping to reduce those barriers or collaborating with immigrant families to create new systems that support educational participation. However, youth in emerging immigrant communities are under-represented in the professional literature. Thus, the current study sought to highlight their voices and perspectives on their future goals.

\section{Review of the Literature}

Researchers have identified many potential explanations for the gap between educational aspirations, expectations, and outcomes for Latina/o students in immigrant families. One set of explanations are systemic, including fewer college preparatory resources and low expectations at the high schools where Latina/o immigrants tend to be enrolled, and school practices like course tracking or cultural marginalization (Hill \& Torres, 2010; Kimura-Walsh, Yamamura, Griffin, \& Allen, 2009). Another set of explanations center on family characteristics, such as low levels of income, low levels of parental knowledge about US educational systems, or barriers to communication with schools (Bohon, Johnson, \& Gorman, 2006; Calaff, 2007; Fann, Jarsky, \& McDonough, 2009; Marquez Kiyama, 2010). A third set of explanations are environmental in nature, including community constraints like gangs or drugs, limited social network of college role models, and cultural and linguistic adjustment (Calaff; Pew Hispanic Center, 2009). Finally, the literature lists individual characteristics that could contribute to the gap, such as English fluency, valuing of family responsibilities over educational aspirations, legal status, or acculturation status (Bohon et al.; Perez, 2010; Pew Hispanic Center; Tseng, 2006).

However, few researchers have examined how Latina/o students in immigrant families conceptualize barriers to college or career. Calaff (2007) published an ethnography focused on the educational pathways of successful Latino immigrant adolescents that mentioned some of the challenging circumstances encountered by these students, but did not attempt to describe barriers. Marquez Kiyama (2010) conducted case study research focused on English-speaking Mexican American parents' knowledge about college preparation that included their perceptions of barriers but not those of their children. Most of the adolescent barriers literature comes from quantitative studies by Flores and colleagues (Flores \& O'Brien, 2002; Ojeda \& Flores, 2008) or McWhirter and colleagues (Flores \& O'Brien, 2002; Luzzo \& McWhirter, 2001; McWhirter, 1997; McWhirter, Hackett, \& Bandalos, 1998; McWhirter, Torres, Salgado, \& Valdez, 2007; Ojeda \& Flores, 2008). None of these studies were focused on Latina/o participants who were recent immigrants. Ojeda and Flores provided confirmation that perception of barriers (a summed score) is a significant negative predictor of educational aspirations in Mexican American high school students in Texas. Flores and O'Brien focused on career development in Mexican American females, concluding from their path analysis that "the presence of support and few 
perceived barriers has a positive effect on career goals" (p. 24). McWhirter verified that Mexican American participants perceived more barriers to education and career than did their White peers, and subsequently created a structural equation model incorporating barriers with multiple other influences on educational expectations (McWhirter et al., 1998). McWhirter and her colleagues (2007) distinguished between internal and external barriers in a later study and used principal components analysis to group findings from a barriers measure according to theme (e.g., financial, relational, motivation). Financial barriers had the highest means for both Mexican American and White students, but there were differences in how the two groups assessed the likelihood of encountering other types of barriers (e.g., relational, ability, preparation/motivation, separation from family). These contributions are important, but have relied upon quantitative measures that have been implemented in varying ways (Luzzo \& McWhirter, 2001; McWhirter, 1997). In addition, they have not been able to list or describe barriers independently generated by the participants or the relationship of barriers to supports or future goals, as a qualitative study could.

Finally, recent immigrants have not been fully addressed in the literature. Whereas traditional settlement areas like California or Texas often have well-established social and educational support programs, more recently emerging immigrant communities may lack those structural supports (Bohon, Macpherson, \& Atiles, 2005). Thus, immigrant adolescents may be struggling with educational or developmental tasks without access to needed resources. One published qualitative study examined the socioemotional challenges of migration in an emerging Latino community from an adolescent point of view, describing social isolation, economic strain, barriers due to English fluency, racism, and legal status (Ko \& Perreira, 2010). To date, no studies have examined barriers to future goals in an emerging immigrant community by listening the voices of the students themselves. Thus, our main research goal was to attend to the voices of students from immigrant families as they reflected on their futures, given the disparity between educational aspirations and actual outcomes reflected in the literature. We wanted to provide insights for counseling professionals who are working with Latina/o immigrant youth regarding their career, academic, and personal concerns in any setting. We also sought to inform the work of advocates seeking to reduce the impact of barriers and improve educational access, as described in the social justice counseling literature (HolcombMcCoy, 2007; Toporek, Lewis, \& Crethar, 2009).

\section{Method}

Consensual qualitative research (CQR) was chosen as an appropriate methodology due to the discovery-based nature of the research question (How would children of immigrant Latina/o families in an emerging community describe their goals for the future and their supports or barriers for reaching them?), the limited state of the current literature, and the interest in attending to the students' experiences (Hill, Thompson, \& Williams, 1997). This approach falls within the qualitative traditions that view reality as a social construction; participants can hold multiple perspectives on the "truth" of their lives, which emerges from the interviews and is subjective (Hill, 2012). The research team valued the opportunity to learn from the participants and actively tried to stay within their interpretive framework when reading and describing the interviews. However, CQR also includes a post-positivistic approach to coding, where several researchers try to reach consensus on the most representative way to depict that subjective truth across the cases (Hill et al., 1997). In particular, the use of a research team and consensus meetings bring multiple perspectives to bear on the data and allow team members to 
share decision and meaning making power (Hays \& Wood, 2011). Typically, findings are also shared with participants as a way to co-create knowledge. In this case, member checks were not possible, because participants were involved in a longitudinal quantitative study regarding peer influence on risk behaviors in the school context. Efforts to share qualitative findings could have biased the ongoing data collection by altering the way the participants thought or felt about supports and barriers in their school environment.

\section{Participants}

The research team received IRB approval to recruit $10^{\text {th }}$ grade Latina/o participants from an existing longitudinal school-based study initiated by one of the current authors. The sites included three high schools in one rural county in the southeastern US, one of which was a dual enrollment school situated on a community college campus. Efforts were made to balance representation of Latina/o $10^{\text {th }}$ graders among the three participating schools and to complete a minimum of 15 interviews. During the recruitment phase, multiple phone numbers were disconnected or had no answer and no voice mail, however, 26 Latina/o families answered the recruitment calls and 23 parents consented to their students' participation in the study. Nineteen $10^{\text {th }}$ grade students also assented to participate and 17 completed the interview. Phone recruitment stopped at that point. Of the participating group, 8 were female and 9 were male, 5 were students in the dual enrollment program and 12 attended traditional high schools, the average age was 16.4 , and 11 of the 17 were born in the US. Thus, the participant group included immigrants and first generation American adolescents. All of the parents were foreign born and the majority had completed a high school diploma or less, as reported by the students. Representative parental occupations included cleaning houses or working in a factory for mothers and construction or landscaping for fathers. Most families were of Mexican origin ( $n=13)$, with others from Central American countries (e.g., Honduras, El Salvador).

\section{Researchers}

The primary research and coding team consisted of two female faculty members (one White, one Latina, both bilingual English and Spanish) and one female doctoral research assistant (White, monolingual English). An undergraduate research associate (Latina, bilingual) obtained consent from the parents, obtained assent from the students, and scheduled the interviews. An external auditor (White female faculty member with previous experience in the chosen methodology) was identified. The three coding team members read materials regarding consensual qualitative research (CQR; Hill et al., 1997; Hill et al., 2005) and discussed the steps of coding during several meetings. The doctoral research assistant completed the participant interviews. She had prior experience collecting qualitative data and also received training and completed practice interviews prior to implementing the protocol. One interviewer was used to increase consistency of data collection. The co-investigators reviewed the transcripts after the first 2-3 interviews to provide constructive feedback to the interviewer in order to maximize the opportunity to collect quality data (e.g., remind her to allow ample space for open-ended responses before moving to the follow-up prompts).

\section{Interview Protocol}

The primary researchers developed the semi-structured interview protocol (available by request from first author) by reviewing the literature related to future aspirations and outcomes for 
Latina/o adolescents in combination with our guiding research question, which was "How would these children of immigrant families in an emerging community describe their goals for the future and their supports or barriers for reaching them?" The following topics of inquiry were identified: (a) hopes for the future in terms of family life, school, and job or career (Fuligni \& Pedersen, 2002; Kao \& Tienda, 1998; McWhirter \& McWhirter, 2008); (b) realistic expectations and worries for the future in those three areas (Oyserman, Bybee, \& Terry, 2006; Yowell, 2000); (c) impact of family, friend, and counselor/teacher relationships on those goals (Hill \& Torres, 2010); (d) identification and perception of barriers to achieving those goals (McWhirter et al., 2007); (e) information or behavior needed to make progress toward those goals (Calaff, 2007; Tseng, 2006); and (f) perspectives on the futures of average Latina/o girls and boys (Kao, 2000). The interview protocol reflected a combination of open-ended questions designed to elicit unbiased responses and more structured prompts designed to provide cognitive support to adolescent participants. For example, after identifying their goals for the future, students were asked, "What could get in the way of meeting that goal?" After encouragement to elaborate independently, students might be prompted with specific barriers from the literature (e.g., "Some other students have said that needing to help their family could get in the way - is that true for you?"). Two test interviews were done with Latina/o adolescents to evaluate length and appropriateness of language, and feedback on the structure and contents of the interview was gathered from a Latina faculty peer; the revised interview was implemented.

\section{Procedure}

Latina/o students with parental consent were offered the opportunity to participate in a 45-60 minute recorded telephone interview in their preferred language for a small gift card incentive. One interview was conducted in Spanish with one of the principal investigators and the rest were conducted in English per student request. Both the sample size and the telephone interview methodology fall within normal practices for in-depth qualitative research (Hill et al., 1997). Participant names were separated from the case numbers, and the de-identified recordings were transcribed and double-checked by undergraduate researchers supervised by the principal investigators.

Before reading any transcripts, the three person coding team bracketed their preconceived notions about the study and participants in separate journal entries. Themes that emerged were discussed among team members at the first coding meeting in order to limit the impact of our assumptions on the coding process. Research team members expected students to mention challenges of being in low-income and/or undocumented families, aspects of their cultural adjustment, high aspirations for education and career, and centrality of family. Some members expected the students to have moderate levels of knowledge of college preparation and English literacy, and others expected lower levels. Research team members referred to the bracketing exercise throughout the coding process when debating the themes in the transcripts and constructing our shared meaning (e.g., deciding whether statements had an underlying cultural perspective or whether that was our own bias in approaching the transcripts).

Without having pre-arranged domains, each team member read the first six transcripts independently and developed language to describe the major themes (or domains). Consensus meetings followed for each transcript; the team rotated roles so that one person would present a case, initiate the dialogue, and record the consensus version. A list of initial domains was created, debated, and revised, resulting in a codebook of five final domains: goals for future, 
roles of other individuals, barriers to future, responsibility, and culture related issues. The coding team then abstracted the core ideas that made up each domain and came to consensus around those. Some of the final domains are similar in structure to the core interview questions, but the contents of the domain were organically derived from the participants' words. We created a brief summary for each case and forwarded it to the external auditor along with copies of the first six transcripts. After receiving constructive feedback on the first six cases from the auditor, the team completed coding domains, abstracting core ideas, and coming to consensus for the remaining 11 cases. The remaining cases did not alter the original domain structure, so the data were deemed to be stable. Finally, cross-analysis was completed by examining domain contents across all 17 cases to look for similarities in the abstracts or connections among the thematic areas. The auditor reviewed the cross-analysis for all cases.

The validation strategy included having a coding team to review and discuss the interview data from various perspectives, creating a codebook after achieving initial consensus to guide further analysis, having an external auditor to review and critique the coding, and comparing interview data with quantitative data gathered as part of the longitudinal study (after coding, so as not to bias analysis). As recommended in CQR, the core ideas that were general (present in $90 \%$ of cases), typical (present in $50 \%$ or more of the cases), or variant (present in less than $50 \%$ of cases) are shown in Table 1 (Hill et al., 2005).

Table 1

Selected Domains and Core Ideas Across All Participant Interviews

\begin{tabular}{lll}
\hline Domain title & Core ideas & Cases (Frequency) \\
\hline Goals for future & Family: Married with children, close to parents & 17 (general) \\
& Career: Hope to enter skilled profession & 17 (general) \\
& Education: Hope to finish "college" & 13 (typical) \\
& "Good life:" Nice house, good job, carefree life & 13 (typical) \\
& Career: Worried about "dead-end" jobs & 11 (typical) \\
Role of other & Education: Concerns about achieving goals & 7 (variant) \\
individuals & Teachers/Counselors: School personnel are helpful, & 16 (general) \\
& could give advice or help if I needed it & 16 (general) \\
& Family: Provides emotional encouragement & 11 in each \\
& Peers: Can be positive or negative influences & direction (typical) \\
& Teachers/Counselors: College role models & 9 (typical) \\
Barriers to & Family: Help with problems or decisions & 5 (variant) \\
future & Teachers/Counselors: Specific advising functions & 3 (variant) \\
& Early pregnancy & 16 (general) \\
& Non-endorsed barriers: being Latina/o, lack of & 13 -14 (typical) \\
& ability in school, friends interfering with plans & \\
& Circumstances beyond control & 9 (typical) \\
& Finances: open-ended and prompted responses & $9-12$ (typical) \\
\hline
\end{tabular}


Table 1, continued

\begin{tabular}{lll}
\hline Domain title & Core ideas & Cases (frequency) \\
\hline Responsibility & Responsibility: "It's all up to me" & 17 (general) \\
& Knowledge: Vague on how to go to college & 16 (general) \\
& Motivation: Related to family & 11 (typical) \\
& Motivation: Want to "be somebody" & 11 (typical) \\
Culture related & Less hopeful view of future for "typical" Latina/o & 12 (typical) \\
& than for themselves & 7 (variant) \\
& Nothing coded under culture & 6 (variant) \\
\hline
\end{tabular}

\section{Findings}

\section{Goals for the Future}

This domain is defined by the participants' reflections on goals for family, education, and career. In terms of family, all students expressed a desire to have a spouse and children in the future, and to maintain a close relationship with their parents (general core idea). In terms of education, a typical core idea was the aspiration to finish "college," with some specifying a 4year degree and others leaving the level unstated. A variant core idea addressed worries about achieving that goal (not making it out of high school, being ineligible for college, not being able to pay for college or pass college-level classes). For example, a young man who wanted to graduate from college indicated he was not worried about completing high school, "because I know I can if I put my mind to it," but admitted to some worries about college. He stated, "Because sometimes I have classes I don't understand and everything. And sometimes worry about not passing and that might bring me down in the future."

A general core idea related to careers was interest in skilled or professional careers (see Table 2). Most students expected to be able to reach those goals. However, when asked about worries, a typical response included worries about not finding any work at all or being stuck in a job they didn't like (with fast food being mentioned several times). When discussing job worries, one student said, "You know, most people don't like their jobs, be like getting up and not wanting to go." Another mentioned, "I don't want to have like a low paying job, I don't want to have to be stressed all the time because I don't have enough money to pay bills and stuff like that." A few students specifically made the connection to the work their parents did, with reflections such as, "My mom didn't go to college and she's all struggling and I want a better life than that," or "If I see Hispanic people, I see them working at factories and stuff like that and then you know, in my viewpoint, I will be like my parents working in a factory. Like that." Often, the same student would mention educational and career aspirations (e.g., "laser and photonic technology") at one moment and anxieties or concerns in the next moment (e.g., "want to avoid a dead-end job"). One student seemed to voice his concerns about a "deadend" job when he said, "A dead-end job is a job where you go every day, you are bored, you don't want to go, it tires you out and you are doing physical work and not mental work." 
Table 2

Participants' Career Goals and Perspectives on "Typical" Latina/o Student

\begin{tabular}{|c|c|}
\hline $\begin{array}{l}\text { Participant } \\
\text { gender }\end{array}$ & Career goal \\
\hline Male 1 & Air Force pilot \\
\hline Male 2 & $\begin{array}{l}\text { Business owner or crime scene } \\
\text { investigator (CSI) }\end{array}$ \\
\hline Female 1 & Emergency technician, CSI \\
\hline Male 3 & Architect, car designer \\
\hline Female 2 & $\begin{array}{l}\text { Massage therapist, own a hair } \\
\text { salon, designer }\end{array}$ \\
\hline Male 4 & Psychologist, laser/photon engineer \\
\hline Male 5 & Military, law enforcement \\
\hline Female 3 & Actress, movie star \\
\hline Male 6 & Electrical engineer, car engineer \\
\hline Female 4 & Teacher or work in a store \\
\hline Male 7 & Mechanic, chef, fireman \\
\hline Female 5 & $\begin{array}{l}\text { Cosmetology, business owner, } \\
\text { teacher }\end{array}$ \\
\hline Female 6 & $\begin{array}{l}\text { Something medical, like a vet or } \\
\text { psychiatrist }\end{array}$ \\
\hline Male 8 & Musician \\
\hline Female 7 & Registered nurse \\
\hline Female 8 & Peace corps, military nurse \\
\hline Male 9 & Graphic designer \\
\hline
\end{tabular}

Career for "typical" Latina/o

He will work, unsure where

McDonalds, construction, poultry

processing

Nurse or store owner

Will finish high school, might work in an

office

Work in a tienda, Latina/o-oriented store

Factory worker, not a manager

Construction or electrician

Lawyer

Mechanic or other minimum wage job

Teacher

Construction

If she finishes HS and college, can get a

good paying job

Office worker or social worker

Fast food job, unless he goes to college

Secretary or paralegal

Factory work

Job depends on what he likes to do and if he tries to go to college

Another typical core idea that emerged was the "good life," reminiscent of the American Dream in its idealized view of success, material possessions, and contentment. Sample statements included, "I hope to just be happy and someday own our house so we don't have to just like pay rent all the time," and "become successful, I guess, really. Like have a good family, good house, good job."

\section{Roles of Other Individuals}

Participants were asked directly how family members could help them reach their future goals, and were also given open-ended opportunities to identify other influential individuals who could provide support. Family played a major role in emotional support of the students' educational goals, with a general core idea encompassing statements like "my family gives me hope, they tell me to work hard and never give up, they will feel proud of me if I finish school, they give me encouragement no matter what." One student expressed the importance of education in immigrant families when he stated, "They want me to be a big person with a career, a college graduate." A variant core idea regarding family was that they could offer some assistance with problem solving and decisions, based on their life experience. Peers were also mentioned, but 
with a distinct split between those who perceived friends as supports and those who perceived them as negative influences who could inhibit progress toward goals.

Students were positive in describing their experiences with school personnel (general core idea). They mentioned that teachers and counselors were usually friendly and ready to help, but some also admitted they had not yet had a conversation with those individuals regarding college planning. Some sample statements included, "You can talk to the teachers if you have questions"; "Teachers talk about college and say its important, but I haven't talked to them about that"; and "Teachers and counselors can give good advice, they are nice and easy to talk to." Most students did not provide specific examples of advice they had received or conversations they had with school personnel, leading to the hypothesis that this resource was relatively untapped. There was a typical core idea that teachers/counselors could be college role models or informants, having completed degrees themselves. Students wanted to hear about what college is like and what to do when applying, given that most of them had few college role models. Finally, a variant core idea included specific functions of teachers and counselors, such as telling students about scholarships, helping with homework or studying, and general advising. One student said teachers and counselors could "Like give references and give good details, good things about me." Very few students mentioned strategic ways to utilize counselors or teachers as supports, such as researching future options or helping with SAT preparations.

\section{Barriers to the Future}

When given an open-ended opportunity to identify things that might get in the way of accomplishing their goals, getting pregnant too early was the only general core idea to emerge. The second most frequently mentioned barrier was financial (a typical core idea), discussed in terms of family debt, low-paying jobs, or having to direct money towards meeting basic needs rather than education. Participants indicated that family might help them pay for college to the extent possible, even amidst financial difficulty. One young man who thought that "the economy is all whack and my parents might need me to get a job for money" also said that his parents could provide him financial support only if he went to college, "but if I dropped out I would have to start working because they won't support that." Lack of money was associated with problems in finishing high school and deciding whether entering and completing college was feasible or not. Finances also were endorsed by 12 students in the prompted section of the interview as "the main concern" or "the only thing that could get in my way." One student said, "If I didn't attend college, it would be because my dad didn't have enough money, but it's going to be OK, we understand they don't have it, but then I'll have to find a scholarship."

Several students also identified a typical core idea of circumstances beyond their control, such as "If classes are too hard, might not be able to complete school ... if economy is bad, may not find good job - things beyond our control," and the sense that "life could happen," anything could get in the way. Another student indicated, "Something could happen, like I could break my arm or someone in my family could get sick." Others addressed competition for jobs, being unjustly accused of breaking a rule at work, or becoming depressed. This typical sense of unspecified disaster was striking in that these may not be the most likely barriers, but these worries were mentioned with some frequency. In contrast, only four students mentioned barriers having to do with academic eligibility. 
When prompted with a list of barriers drawn from the literature, participants were optimistic about having the academic ability to complete their educational goals, being able to overcome any negative peer influences, and finding sufficient support despite being Latina/o in a state that has an emerging immigrant community and few established structural supports. When asked if they would need to change their educational plans to help family members, most respondents said no, but usually qualified it by mentioning that if a specific request for help came from family members, they would not hesitate to respond. Thus, the students were more likely to deny than to endorse the pre-identified barriers presented in the interview.

\section{Responsibility}

There was a strong general theme about personal responsibility for bringing educational and career dreams to fruition, identifiable in all students at varying levels of emphasis. The first level was present in five cases, and it described a sense of disappointment if goals were not met, mostly attributed to behavior. Some examples were, "It's up to me if I don't meet my goal, maybe I didn't study enough"; "I would be disappointed, but I would try again later"; and "It all depends on what I do, but if I don't meet my goals, at least I tried." The second level was present in six cases, and it included more emphatic language regarding responsibility. Those statements were, "I must be responsible, study, get good grades, and work to make it happen. [Who can help you?] Myself"; "If I didn't meet my goals, I would say I screwed up"; and "It is my own fault because I can be anything I want to be." The third level was also noted in six cases, and was characterized by catastrophizing or blaming self in strong language. These students stated, "I would wake up every day thinking I was a failure"; "I would blame myself as a bad person, that I didn't try hard enough, life would suck"; "My life would be ruined, I would be mad and think what a waste of time and money"; and "I will feel really miserable, always dreaming about this other career, I would feel like a failure and ashamed to see my Mom."

Motivation to succeed was another theme under the responsibility domain. A typical motivation core idea linked the desire for a better future to family-related variables, such as wanting to make parents proud, wanting to be the first in the family to graduate from college, wanting to be in a position to provide for future offspring in a way that their parents could not, not wanting to disappoint family, and hearing messages at home such as "don't be like me." There was also a core idea of personal motivation, sometimes overlapping in the same individual case with family-related motivation. One student stated, "I want to reach my goals and dreams and I want to succeed in life - I don't want to struggle. I want to be the first one out of my whole family that actually goes to a university." Personal motivation also revolved around wanting to make career dreams come true, wanting to feel like "somebody" or to have accomplishments, and wanting a better life than their present circumstances. One student reflected on family members who had dropped out of school for various reasons, and said, "I decided I would be different, I would actually go to school." Some students described particular aspects of their context, such as seeing a bad economy and realizing how a high school diploma would be necessary, or living in the US with "a whole bunch of possibilities, so what can't I do?"

The final general core idea in the responsibility domain related to knowledge or strategies of how to reach one's goals. Some sample quotes were to "get good grades"; "study for and pass the end of year test"; "pay attention in classes and not fail any"; and "take the right classes." In a related way, students discussed how they needed to "work better, straighten up, always 
try"; or "forget about parties and focus on studying, pay attention, put in effort and not get messed up." These fairly brief comments had a positive tone, but also an overly general quality. There was almost no mention of the sequential tasks that are part of planning for future education or career.

The interviewer then prompted the students regarding some standard tasks for college preparation, such as the need for taking the SATs, places to look for college information, people to talk with during the process, grades or classes that might be required, and steps currently being taken by the student. Some sample responses included, "I think I have to take the SATs, but I'm not really sure how"; "I don't know who I would talk to - maybe my aunt who graduated from college?"; "would need math and English, at least with a high B"; and "I think I could look for information on the internet."

\section{Culture}

This domain was utilized whenever the participants directly addressed being Latina/o as part of their responses, such as stating "some people think Latinos don't belong here, that we are not welcome." In one section of the interview, students were asked as a follow up, "Is it hard to be Latino in a state like this one?" Culture was also addressed directly in the section of the interview where participants were asked their view of the future for a typical Latina/o student. Thus, the researchers activated the notion of culture and then probed for family, education, and career outcomes for other Latinas/os. A typical core idea was that the average Latina/o student would achieve less education or a less prosperous career than the respondent. As seen in Table 2, participants had high aspirations for themselves but were more stereotypical in their list of likely careers for other Latinas/os.

Variant core ideas related to culture included no spontaneous mentions of culture during the interview and mixed mentions of the positive and negative aspects of culture. One example of the latter was, "Money problems - that's like our main thing, being Latinos. But, on the good side, some people want to hire us because of being bilingual." Another student said, "Being an immigrant here is hard. People don't have driver's licenses so if you miss the bus to school, they can't take you. But in school, there are ESL classes and teachers to help us, so that part is good."

In terms of comparing these qualitative findings with the longitudinal quantitative survey, both sets of data reflected the students' interest in college. In the survey, $47 \%$ of participants stated their chances of attending college as "high to very high" and $47 \%$ selected "about $50 \%$ chance". Participants also believed that their lives would be better than their parents' (with $88 \%$ endorsing "high to very high" chances). In terms of barriers, the quantitative data showed that students were not concerned with issues related to being an immigrant (with $65 \%$ selecting not at all) or worried about getting poor grades (with 59\% selecting not at all).

\section{Discussion}

The researchers sought to augment the existing literature on future educational or career aspirations by attending to the voices of Latina/o adolescents in emerging immigrant communities. The findings in the current study parallel the literature about Latina/o immigrant 
families in that parental encouragement and student aspirations/motivation for the future are strong, educational legacy or specific knowledge of steps and strategies are at low levels, and finances are a concern (Marquez Kiyama, 2010). This study makes a contribution to the existing literature in the following way: (a) a qualitative approach to supports and barriers to future goals; (b) a focus on the unique sense of responsibility for success or failure held by the students; (c) a comparison between outcomes for self and for an "average" Latina/o; and (d) the addition of an emerging immigrant community as context. The discussion utilizes a social justice counseling perspective, which includes an examination of the interplay between individual aspirations and the social power dynamics that make progress toward those goals more difficult for some groups.

\section{Perception of Barriers}

Whereas the quantitative literature would lead one to anticipate many barriers for ethnic minority students in these life circumstances (Luzzo \& McWhirter, 2001), the participants reported relatively few. Of the barriers presented on the Perceptions of Barriers and Perceptions of Educational Barriers measures in prior studies (Luzzo \& McWhirter, 2001; McWhirter, 1997), only pregnancy and financial concerns were echoed by the current participants. The students added a sense of "circumstances beyond one's control" as a potential barrier, which could be consonant with a cultural attitude of fatalism or a reflection of the precarious circumstances of a recently immigrated family. The participants declined to endorse suggestions of barriers related to academic preparation, lack of support, not being smart enough, family obligations, or experiencing negative attitudes from others due to their ethnicity.

In addition, the qualitative coding process illuminated some potential barriers that were not directly identified as such by the students. Even though most of them would be the first in their families to enter college, they did not mention a lack of role models as a limiting factor. Other themes that were described by the participants but not directly identified as barriers included relatively low levels of knowledge of the educational system or few strategies for college planning, missed opportunities for obtaining support from teachers and counselors, and fears regarding "dead-end" jobs and poor educational outcomes for Latina/o immigrants. Possible explanations for the low perception of barriers include the age of the participants, who perhaps still saw college and career planning as distant tasks, a lack of critical consciousness of the power structures that might disadvantage them, a lack of connection with knowledgeable mentors or guides, or the immigrant optimism that regards the US as a land of opportunity for those who work hard and thus may obscure systemic barriers (Yowell, 2000).

\section{Emotional Support and Instrumental Support}

There could be benefits as well as drawbacks to the lack of perceived barriers. A positive view of the resiliency and cultural capital of immigrant families may provide an explanation for the paucity of identified barriers (Ceja, 2004; Shetgiri et al., 2009). Even in a context with few culturally-relevant role models or structural supports, students had high aspirations in terms of both education and career. They believed that hard work would be enough to achieve their goals and knew their families supported them. The protective influence provided by families' emotional encouragement and reminders of the reasons for emigrating to the US could increase students' coping efficacy and positive outcome expectations (Lent et al., 1994). 
Unfortunately, most students had very little specific knowledge or useful strategies about how to fortify their path into college, which parallels findings from previous studies (Yowell, 2000). Although their motivation was undeniable, they did not identify the instrumental supports that would aid them in translating their vision into a reality of college access and professional work. School counselors and teachers would be appropriate sources for this missing strategic information; however, students seemed to be underutilizing these resources. The reason for these missed opportunities did not seem to be overt discrimination or unhelpful attitudes on the part of school personnel, as most students had a positive perception of teachers and counselors. Possible reasons for not seeking help for college preparation could include lack of developmental readiness to undertake college planning tasks, lack of awareness of the complexity of the college planning and admissions process, difficulty in accessing support services, or cultural preference to receive advice from trusted members of one's social network (Kimura-Walsh et al., 2009; O'Connor, 2009). This barrier could be described as lack of understanding of how to engage with an unfamiliar system, which is logical to expect from immigrant families. This suggests that social justice advocates could empower students and families simply by making the educational system less opaque and thus more truly accessible.

Missed opportunities for engagement could also be viewed from the counselors' and educators' side. Under-represented populations with few college role models who do not know the questions to ask or the appropriate timeline for planning may require proactive outreach efforts (National Postsecondary Education Cooperative, 2007). School counselors can be influential in providing college information and planning support to students; however, this input may be absent in situations such as high poverty high schools, where inexperienced counselors may have many other duties or may hold low college expectations for some students based on stereotypes (Bryan, Holcomb-McCoy, Moore-Thomas, \& Day-Vines, 2009; Cabrera \& LaNasa, 2000; Gandara \& Bial, 1999). It is clear that participants in this study benefited from counselors and teachers who initiated conversation about the importance of college or their personal experiences in higher education. Proactive and strengths-based interventions are key from a social justice counseling point of view with vulnerable populations (Holcomb-McCoy, 2007).

\section{Barriers and Responsibility}

In the relative absence of identified barriers, students seemed to blame themselves for not working hard enough if they could not achieve their dreams. Perceived external barriers to college (such as lack of money, policies and laws, or school and community demographic context) would allow students to make attributions that did not place primary responsibility with themselves (Lent, Brown, \& Hackett, 2000). However, participants in this study did not blame schools with few resources or anti-immigrant laws when asked what could prevent them from reaching their goals. Instead, these students named internal barriers such as not working hard enough, giving up, or not following through. They were laudable in their sense of effort and responsibility, but also unaware other circumstances might become a barrier. A social justiceminded counselor might consider whether internalized oppression was influencing student perceptions of their own role in actualizing their futures. This could lead to strategies for building critical consciousness of the structural barriers that impede progress, relieving students of the self-blaming attitudes that could harm them psychologically (Holcomb-McCoy, 2007). 


\section{Stereotypes as Barriers}

Finally, the contrast between what students hoped was possible in their futures and what they feared would occur or believed was likely for a typical Latina/o student is noteworthy. As individuals, they were motivated about fulfilling the American dream and accessing "the good life." They believed they could create a future that would defy the stereotypes. However, when reflecting on their group as represented by a "typical" Latina/o, they became increasingly doubtful that educational and career attainment were likely and instead mentioned the types of work they observed others performing in their community (as seen in Table 2). When culture was activated in their minds by the phrasing of the question, they were no longer as optimistic about "typical" Latinas/os achieving the things they themselves were hoping to complete. Particularly in a new immigrant community with fewer visible examples of high career and educational attainment and the presence of anti-immigrant rhetoric, it is plausible that the participants had absorbed negative stereotypes about their own group. It is also possible that their lack of familiarity with the mechanisms for moving into college and career left them with no other explanation; if I can't do it, it must be my fault, and if typical Latinas/os can't do it, it must be their fault. These themes strongly suggest the presence of internalized oppression paired with a lack of perspective on pervasive systems of social advantage and disadvantage, which leaves individuals with an inaccurate understanding of their position in the power structure.

\section{Emerging Immigrant Communities}

The juxtaposition of high aspirations, few identified barriers, strong fears, and self-blame in these findings is striking. Compared with the risk and resilience model described by Ko and Perreira (2010) in a similar emerging immigrant community, the current study also underscores the mixed experience of adjusting to a culture that is not fully prepared to support newcomers. In a new context, immigrant families may not understand fully the systems with which they must interact (e.g., schools, work places, laws). However, in the scope of these interviews, students did not report members of those systems reaching out to engage them. This lack of information or social isolation can limit opportunity, even among motivated and capable individuals (Bohon et al., 2005; Ko \& Perriera, 2010). The contrasts present in these qualitative interviews may illustrate the mixed influences the students were trying to process from their families, their schools, their peers, and the local community, or their lack of perspective on how one moves from the abstract world of aspirations to the concrete world of planning and preparation.

\section{Implications for Counselors: Intervention and Advocacy}

One implication of our findings is that students from immigrant families have strengths and resources, but also have some unmet needs in terms of engaging with the college preparation process. Although this study cannot confirm whether supplying missing information would be sufficient to address those needs, providing knowledge and empowerment for applying that knowledge could be one starting place (Borders, Hines, Gonzalez, Villalba, \& Henderson, 2011). Counselors and educators can help immigrant families see into the black box of educational planning, so that the path from aspirations to attainment is no longer hidden from their view. Rather than maintaining the status quo of educational access for privileged families alone, such an intervention represents counselor advocacy for students who have been ignored or left 
behind (Holcomb-McCoy, 2007). To be done in a culturally effective way, this could include Spanish-speaking parents and students as role models (Auerbach, 2004). These inequities in access can be addressed with individual students and families, but it is even more powerful for counselors to examine how future planning is addressed in the school as a whole or the way information is shared with families who speak a language other than English. In this way, even students who identify few barriers to their future plans begin to understand the planning timeline and are included in educational planning conversations.

The hopes, fears, and sense of responsibility expressed by students in this study suggest that interventions may need to address an individual's emotions as well. The theme of personal responsibility for future outcomes has implications for counselors or helping professionals working as advocates. While the cultural implications of these statements by Latina/o immigrant adolescents need to be further unpacked, a critical consciousness may help these youth understand that they are not solely to blame if they fall short of their goals (HolcombMcCoy, 2007). In general terms, an overwhelming sense of responsibility could be paralyzing, so that high aspirations are not acted upon due to fears, stereotypes, and concerns not to be "a failure." Mental health professionals should consider depressive symptoms arising from perceptions of having sole responsibility for future outcomes, and advocates should continue to challenge external structural barriers (e.g., inequitable policies and practices).

Alternately, responsibility can be motivating, and if students can be encouraged to focus on their own sense of agency in combination with responsibility and an understanding of the social power structure, they might be able to see places where they can move forward. From a social justice counseling perspective, a more adaptive message might include the benefits of persistence and hard work, but also an exploration of social systems that confer advantage on some and constraints on others (Holcomb-McCoy, 2007). Increasing a student's sense of agency is one of the final steps in building critical consciousness.

Broader social transformation is important as well. Toporek et al (2009) helped counselors categorize types of advocacy activities they could undertake on behalf of clients and families, from individual to community to large-scale public efforts. To apply those scales of effort toward working for educational and career access with students in emerging immigrant communities, counselors and counselor educators can: (a) empower individual students to keep their high aspirations, encourage them to respond to the stereotypes and/or barriers they perceive, and help them understand power structures they might not initially perceive; (b) advocate for families to receive needed information and resources for future planning in Spanish; (c) collaborate with Latina/o immigrant students and others who experience oppression to deconstruct the blaming sense of responsibility for future outcomes; (d) prepare current and future school counselors to provide more intentional outreach around strategic planning, such that immigrant students are proactively provided opportunities to discuss their future plans; and (e) work in partnership with the immigrant community and the media to bring attention to policies like the DREAM Act. These suggestions are relevant to the themes uncovered in this study because they help to build critical consciousness and human agency amongst students who are confronting barriers, both seen and unseen. Although options for college admission and financial aid are few for the undocumented portion of the community, a few sources do exist. Interested readers are referred to the Mexican American Legal Defense and Education Fund at www.maldef.org or the Hispanic Scholarship Fund at www.hsf.net/. 


\section{Limitations and Implications for Research}

A methodological limitation to the current study is lack of member checks, for reasons described earlier. However, if member checks had been possible, researchers would have been interested in soliciting feedback about the perceived accuracy of the domain titles and core ideas, collaborating on the interpretive validity of the discussion, and gathering any post-interview reflections the participants had about their future goals and plans. In addition, the developmental level of the adolescent participants, their level of comfort with English vocabulary, or the tendency to provide socially desirable answers may have limited responses to the interview prompts. Finally, the follow-up prompts about barriers drawn from the literature could have biased students' responses, even though they were offered in a non-directive manner. Nevertheless, this study can stimulate future research and practice regarding: (a) low levels of knowledge or awareness of steps in college planning; (b) limited use of teachers and counselors to fill in identified gaps in instrumental support; (c) potential interference from stereotypes; (d) the qualitatively constructed relationship between supports, barriers, and goals; and (e) internalization of responsibility for falling short of goals. The CQR methodology can also be a tool for social justice researchers, as a form of learning from and collaborating with participants rather than objectifying them or replicating social biases about the deficits of immigrant communities.

\section{Conclusions}

In summary, attending to the first person perspectives of these students from Mexican and Central American immigrant families provides a more nuanced understanding of what barriers to college and career may be perceived as salient, how unidentified barriers may be operating to limit opportunity, and how perceptions of personal responsibility and culture factor in. From a social justice counseling point of view, educational and career planning is an important area for advocacy as it can bring a greater sense of agency and progress to a disempowered community. This study includes the strengths and optimism of these families, and encourages counselors and advocates to work collaboratively with Latina/o immigrant students to identify and address systemic barriers to progress.

Author Note: The authors wish to thank L. DiAnne Borders for her thoughtful assistance with this study.

\section{Contact information:}

Laura M. Gonzalez

Department of Counseling and Educational Development, The University of North Carolina at Greensboro, PO Box 26170, Greensboro, NC 27402

Email: Imgonza2@uncg.edu 


\section{References}

Auerbach, Susan. (2004). Engaging Latino parents in supporting college pathways: Lessons from a college access program. Journal of Hispanic Higher Education, 3, 125-145.

Bohon, Stephanie A, Johnson, Monica K, \& Gorman, Bridget K. (2006). College aspirations and expectations among Latino adolescents in the United States. Social Problems, 53(2), 207-225.

Bohon, Stephanie A, Macpherson, Heather, \& Atiles, Jorge H. (2005). Educational barriers for new Latinos in Georgia. Journal of Latinos and Education, 4(1), 43-58.

Borders, L.D, Hines, E.M, Gonzalez, L.M, Villalba, J.A, \& Henderson, A. (2011). Parental involvement in college planning: $A$ report for the College Foundation of North Carolina (CFNC). Greensboro, NC: CFNC.

Bryan, Julia, Holcomb-McCoy, Cheryl, Moore-Thomas, Cheryl, \& Day-Vines, Norma L. (2009). Who sees the school counselor for college information? A national study. Professional School Counseling, 12(4), 280-291.

Cabrera, Alberto F., \& LaNasa, Steven M. (2000). Understanding the college-choice process. In A. F. Cabrera \& S. M. LaNasa (Eds.), Understanding the college choice of disadvantaged students (Vol. 107, pp. 5-22). San Francisco: Jossey-Bass.

Calaff, Kristin Percy. (2007). Latino students' journeys toward college. Bilingual Research Journal, 31(1/2), 201-225. doi: 10.1080/15235880802640680

Ceja, Miguel. (2004). Chicana college aspirations and the role of parents: Developing educational resiliency. Journal of Hispanic Higher Education, 3(4), 338-362. doi: $10.1177 / 1538192704268428$

Fann, Amy, Jarsky, Karen McClafferty, \& McDonough, Patricia M. (2009). Parent involvement in the college planning process: A case study of P-20 collaboration. Journal of Hispanic Higher Education, 8, 374-393. doi: 10.1177/1538192709347847

Flores, Lisa Y., \& O'Brien, Karen M. (2002). The career development of Mexican American adolescent women: A test of social cognitive career theory. Journal of Counseling Psychology, 49(1), 14-27. doi: 10.1037/0022-0167.49.1.14

Fuligni, Andrew J., \& Pedersen, Sara. (2002). Family obligation and the transition to young adulthood. Developmental Psychology, 38(5), 856-868. doi: 10.1037/00121649.38.5.856

Gandara, Patricia, \& Bial, D. (1999). Paving the way to higher education: K-12 intervention programs for underrepresented youth. Washington, DC: National Postsecondary Education Cooperative. 
Hays, Danica G., \& Wood, Chris. (2011). Infusing qualitative traditions in counseling research designs. Journal of Counseling \& Development, 89(3), 288-295.

Hill, Clara E. (2012). Consensual qualitative research: A practical resource for investigating social science phenomena. Washington, DC US: American Psychological Association.

Hill, Clara E., Knox, Sarah, Thompson, Barbara J., Williams, Elizabeth Nutt, Hess, Shirley A., \& Ladany, Nicholas. (2005). Consensual qualitative research: An update. Journal of Counseling Psychology, 52(2), 196-205. doi: 10.1037/0022-0167.52.2.196

Hill, Clara E., Thompson, Barbara J., \& Williams, Elizabeth Nutt. (1997). A guide to conducting consensual qualitative research. The Counseling Psychologist, 25(4), 517-572. doi: $10.1177 / 0011000097254001$

Hill, Nancy E., \& Torres, Kathryn. (2010). Negotiating the American dream: The paradox of aspirations and achievement among Latino students and engagement between their families and schools. Journal of Social Issues, 66(1), 95-112. doi: 10.1111/j.15404560.2009.01635.x

Holcomb-McCoy, Cheryl. (2007). School counseling to close the achievement gap: A social justice framework for success. Thousand Oaks, CA US: Corwin Press.

Kao, Grace. (2000). Group images and possible selves among adolescents: Linking stereotypes to expectations by race and ethnicity. Sociological Forum, 15(3), 407-430. doi: 10.1023/a:1007572209544

Kao, Grace, \& Tienda, Marta. (1998). Educational aspirations of minority youth. American Journal of Education, 106, 349-384.

Kimura-Walsh, Erin, Yamamura, Erica K., Griffin, Kimberly A., \& Allen, Walter R. (2009). Achieving the college dream?: Examining disparities in access to college information among high achieving and non-high achieving Latina students. Journal of Hispanic Higher Education, 8(3), 298-315.

Ko, Linda K., \& Perreira, Krista M. (2010). "It turned my world upside down": Latino youths' perspectives on immigration. Journal of Adolescent Research, 25(3), 465-493. doi: $10.1177 / 0743558410361372$

Lent, Robert W., Brown, Steven D., \& Hackett, Gail. (2000). Contextual supports and barriers to career choice: A social cognitive analysis. Journal of Counseling Psychology, 471 ), 3649. doi: $10.1037 / 0022-0167.47 .1 .36$

Luzzo, Darrell Anthony, \& McWhirter, Ellen Hawley. (2001). Sex and ethnic differences in the perception of educational and career-related barriers and levels of coping efficacy. Journal of Counseling \& Development, 79(1), 61. 
Marquez Kiyama, Judy. (2010). College aspirations and limitations: The role of educational ideologies and funds of knowledge in Mexican American families. American Educational Research Journal, 1-27. doi: 10.3102/0002831209357468

McWhirter, Ellen H. (1997). Perceived barriers to education and career: Ethnic and gender differences. Journal of Vocational Behavior, 50, 124-140.

McWhirter, Ellen H, Hackett, Gail, \& Bandalos, Deborah L. (1998). A causal model of the educational plans and career expectations of Mexican American high school girls. Journal of Counseling Psychology, 45, 166-181.

McWhirter, Ellen $\mathrm{H}$, \& McWhirter, Benedict T. (2008). Adolescent future expectations of work, education, family, and community: Development of a new measure. Youth and Society, $40,182-202$.

McWhirter, Ellen Hawley, Torres, Danielle M., Salgado, Susana, \& Valdez, Marina. (2007). Perceived barriers and postsecondary plans in Mexican American and White adolescents. Journal of Career Assessment, 15(1), 119-138. doi: 10.1177/1069072706294537

National Postsecondary Education Cooperative. (2007). Deciding on postsecondary education: Final report. Washington, DC: National Center for Education Statistics.

O'Connor, Noga. (2009). Hispanic origin, socio-economic status, and community college enrollment. Journal of Higher Education, 80, 121-145.

Ojeda, Lizette, \& Flores, Lisa Y. (2008). The influence of gender, generation level, parent's education level, and perceived barriers on the educational aspirations of Mexican American high school students. The Career Development Quarterly, 571), 84-95.

Oyserman, Daphna, Bybee, Deborah, \& Terry, Kathy. (2006). Possible selves and academic outcomes: How and when possible selves impel action. Journal of Personality and Social Psychology, 91(1), 188-204. doi: 10.1037/0022-3514.91.1.188

Patten, E. (2012). Statistical Portrait of the Foreign-born Population in the United States, 2010. Washington, DC: Pew Hispanic Center.

Perez, Patricia A. (2010). College choice process of Latino undocumented students: Implications for recruitment and retention. Journal of College Admission(206), 21-25.

Pew Hispanic Center. (2009). Between two worlds: How young Latinos come of age in America. Washington, DC: Pew Hispanic Center.

Shetgiri, Rashmi, Kataoka, Sheryl H., Ryan, Gery W., Askew, Lawren Miller, Chung, Paul J., \& Schuster, Mark A. (2009). Risk and resilience in Latinos: A community-based participatory research study. American Journal of Preventive Medicine, 376), S217S224. doi: 10.1016/j.amepre.2009.08.001 
Toporek, Rebecca L., Lewis, Judith A., \& Crethar, Hugh C. (2009). Promoting systemic change Through the ACA advocacy competencies. Journal of Counseling \& Development, 87(3), 260-268.

Tseng, Vivian. (2006). Unpacking immigration in youths' academic and occupational pathways. Child Development, 775), 1434-1445. doi: 10.1111/j.1467-8624.2006.00946.x

Yowell, Constance M. (2000). Possible selves and future orientation: Exploring hopes and fears of Latino boys and girls. The Journal of Early Adolescence, 20(3), 245-280. doi: $10.1177 / 0272431600020003001$ 